\title{
Enhanced Mechanical and Thermal Strength in Mixed-Enantiomers- Based Supramolecular Gel
}

\author{
Daníel Arnar Tómasson, ${ }^{\dagger, \|}$ Dipankar Ghosh, ${ }^{\dagger, \|}$ Zala Kržišnik, ${ }^{\dagger}$ Luiz Henrique Fasolin, ${ }^{\ddagger}$
}

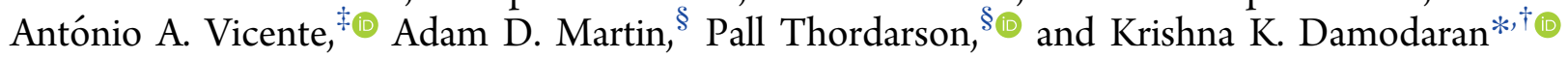

${ }^{\dagger}$ Department of Chemistry, Science Institute, University of Iceland, Dunhagi 3, 107 Reykjavík, Iceland

${ }^{\ddagger}$ Centre of Biological Engineering, University of Minho, Campus de Gualtar, 4710-057 Braga, Portugal

${ }^{\S}$ School of Chemistry, The Australian Centre for Nanomedicine and the ARC Centre of Excellence in Convergent Bio-Nano Science and Technology, University of New South Wales, Sydney 2052, Australia

\section{Supporting Information}

ABSTRACT: Mixing supramolecular gels based on enantiomers leads to re-arrangement of gel fibers at the molecular level, which results in more favorable packing and tunable properties. Bis(urea) compounds tagged with a phenylalanine methyl ester in racemic and enantiopure forms were synthesized. Both enantiopure and racemate compounds formed gels in a wide range of solvents and the racemate (1-rac) formed a stronger gel network compared with the enantiomers. The gel $(\mathbf{1 R + 1 S})$ obtained by mixing equimolar amount of enantiomers (1R and 1S) showed enhanced mechanical and thermal stability compared to enantiomers and racemate gels. The preservation of chirality in these compounds was analyzed by circular dichroism and optical

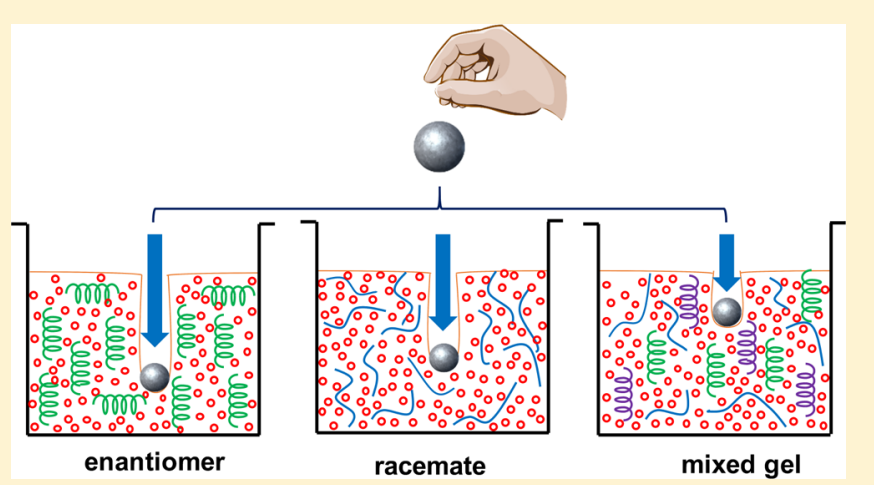
rotation measurements. Analysis of the scanning electron microscopy (SEM) and atomic force microscopy (AFM) images revealed that the network in the mixed gel is a combination of enantiomers and racemate fibers, which was further supported by solid-state NMR. The analysis of the packing in xerogels by solid-state NMR spectra and the existence of twisted-tape morphology in SEM and AFM images confirmed the presence of both self-sorted and co-assembled fibers in mixed gel. The enhanced thermal and mechanical strength may be attributed to the enhanced intermolecular forces between the racemate and the enantiomer and the combination of both self-sorted and co-assembled enantiomers in the mixed gel.

\section{INTRODUCTION}

Supramolecular gels based on low-molecular-weight gelators (LMWGs) ${ }^{1-9}$ have witnessed a tremendous growth over the last decade due to their emerging potential applications ${ }^{10-16}$ such as dynamic gels, biological applications using gels as cell growth scaffolds and also as a medium to control crystal growth, drug delivery, etc. Although the majority of these gelators are based on individual molecules, gels based on multicomponent systems have emerged as smart materials due to their application in tuning gel state properties. ${ }^{17-30}$ Multicomponent gels are formed when two or more components are mixed together in a well-defined stoichiometry and also by introducing an external entity such as nanoparticles $^{31}$ graphene, ${ }^{32,33}$ carbon nanotubes, ${ }^{34}$ clay nanosheets, ${ }^{35}$ liquid crystal, ${ }^{36}$ surfactants, ${ }^{37,38}$ and polymers ${ }^{39-41}$ to an individual system to trigger gelation process. Multicomponent gels based on mixing individual gels are less explored, which will lead to the co-assembly or self-sorting of individual gels either constructively or destructively, resulting in mixtures of gel and crystals ${ }^{42}$ or "multi-gelator" gels. ${ }^{20,43-45}$ The self-sorting processes of multicomponent gels can be analyzed by various analytical methods (NMR, X-ray diffraction, etc. $)^{8,45,46}$ and also by direct and real-time imaging of self-sorted supramolecular fibers. ${ }^{47}$ However, predicting the formation of co-assembled or self-sorted multicomponent gels is challenging due to differences in their mutual interactions and the gelation conditions. The co-assembly and self-sorting is often dictated by the structural similarity between individual gels. ${ }^{18}$ An excellent strategy is to use enantiomers, for example, chiral gels to design multicomponent systems with structurally similar components.

Chiral LMWGs have proved to be an excellent class of soft materials $^{14,43,48-50}$ due to their potential applications in the field of asymmetric catalysis, chiral nanomaterials, and chiral recognition. Gel fibers often show chirality at a mesoscopic scale, which is evident from their morphology (helical cylinders or multiple helices), ${ }^{48}$ and Gunnlaugsson and Pfeffer's group showed that chirality of the gelator dictates the self-assembly

Received: August 10, 2018

Revised: September 27, 2018

Published: October 1, 2018 
processes of gels resulting in the formation of helical materials. ${ }^{51}$ Chirality plays an important role in controlling and mediating the self-assembly of LMWGs, which clearly explains the occurrence of stereogenic centers ${ }^{14,43,48,49,52}$ in most LMWGs. LMWGs based on enantiomerically pure chiral molecules display strong gelling ability compared to their racemates. ${ }^{43,46,53,54}$ Interestingly, when pure enantiomers are less efficient gelators or nongelators, a reverse phenomenon is observed. ${ }^{55-62}$ A racemate LMWG can be considered as a multicomponent gel, where two structurally similar compounds are present in stoichiometric ratio. Mixing of enantiomers leads to self-recognition at the molecular level and pure enantiomers would interact with enantiomers, which may lead to more favorable packing and better gels. ${ }^{18,63-65}$

Multicomponent self-assembled gels obtained by mixing enantiomers have shown different properties compared to the individual gels. ${ }^{63,65-69}$ For example, Schneider's group reported that mixing an equimolar ratio of enantiomers enhanced the mechanical strength of amino acid-based gels. ${ }^{67,70}$ This is due to the structural similarity of enantiomers, which will either self-sort or co-assemble depending on the environment. Self-sorting occurs when enantiomers independently assemble and retain their chirality, whereas in the case of co-assembly, it may result in random or specific co-assembly similar to its racemate (Scheme 1). In a mixed enantiomer

Scheme 1. Self-Assembly Modes in Mixed Gels

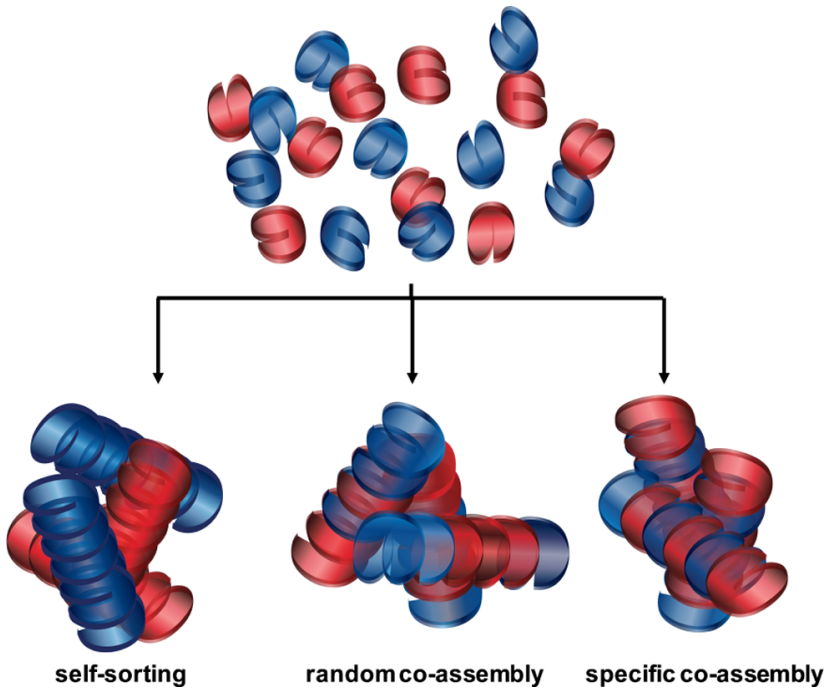

system, the interaction of enantiomers with the same conformation results in separate aggregates via self-sorting, which may lead to conglomerate formation. ${ }^{18}$ Based on their studies on amphipathic peptides, Nilsson and co-workers proposed that enantiomers form co-assembled rippled $\beta$-sheet fibrils rather than self-sorting. ${ }^{63}$ In this work, we have designed multicomponent gels based on amino acid compounds to analyze the difference between the self-assembly of pure and mixed enantiomers. Enantiomeric multicomponent gels based on amino acid derivatives are ideal candidates due to the fact that they are available in enantiomeric and racemic forms, easily accessible, relatively cheap, and easy to modify the substituent groups. ${ }^{64}$

\section{EXPERIMENTAL SECTION}

Materials and Methods. All the starting materials and reagents were commercially available (Sigma Aldrich) and used as supplied. Deionized water was used for gelation test and solvent chloroform was distilled over $\mathrm{P}_{2} \mathrm{O}_{5}$, and methanol over $\mathrm{Mg}$ turnings in the presence of small amount of iodine.

Synthesis. Methyl-rac-phenylalaninate. Five grams $(30.0 \mathrm{mmol})$ of rac-phenylalanine was dissolved in $70 \mathrm{~mL}$ of methanol and $2 \mathrm{~mL}$ of conc. $\mathrm{H}_{2} \mathrm{SO}_{4}$ was added. The solution was refluxed overnight and then cooled to room temperature. Methanol was evaporated and the white oil obtained was stirred with $2 \% \mathrm{NaHCO}_{3}$ solution. The solution was extracted with DCM $(3 \times 75 \mathrm{~mL})$, the combined organic layers were dried over $\mathrm{Na}_{2} \mathrm{SO}_{4}$ and evaporated to yield the ester as white powder. Yield: $4.99 \mathrm{~g}, 92 \% .{ }^{1} \mathrm{H}$ NMR $\left(400 \mathrm{MHz}, \mathrm{CDCl}_{3}\right): \delta[\mathrm{ppm}]=7.32-$ $7.18(\mathrm{~m}, 5 \mathrm{H}), 3.74(\mathrm{dd}, J=8.0,5.2,1 \mathrm{H}), 3.72(\mathrm{~s}, 3 \mathrm{H}), 3.09(\mathrm{dd}, J=$ $13.5,5.1,1 \mathrm{H}), 2.86(\mathrm{dd}, J=13.5,7.9,1 \mathrm{H}), 1.47(\mathrm{~s}, 2 \mathrm{H})$.

General Synthesis of $R-R$ Bis(urea) (1R) and S-S Bis(urea) (1S) Compounds. The phenylalanine methyl ester hydrochloride (1.3 g, $6.0 \mathrm{mmol}$, either $\mathbf{R}$ or $\mathbf{S}$ ) was dissolved in $60 \mathrm{~mL}$ chloroform and 3 $\mathrm{mL}$ of trimethylamine was added. A solution of 1,6-disocyanatohexane $(482 \mu \mathrm{L}, 3.0 \mathrm{mmol})$ in chloroform $(40 \mathrm{~mL})$ was added dropwise under $\mathrm{N}_{2}$ atmosphere over a period of $1 \mathrm{~h}$. The solution was then refluxed at $60{ }^{\circ} \mathrm{C}$ overnight, cooled to room temperature and the solvent was evaporated to yield a white oil. The oil was dried in air and suspended in $50 \mathrm{~mL}$ distilled water and stirred. The suspension was filtered, washed with ethyl acetate, and dried to yield the desired product as a white powder.

1R: Yield: $1.50 \mathrm{~g}, 95.0 \% .{ }^{1} \mathrm{H}$ NMR $\left(400 \mathrm{MHz}, \mathrm{DMSO}-d_{6}\right) \delta 7.31-$ $7.13(\mathrm{~m}, 10 \mathrm{H}), 6.11(\mathrm{~d}, J=8.2 \mathrm{~Hz}, 2 \mathrm{H}), 6.05(\mathrm{t}, J=5.7 \mathrm{~Hz}, 2 \mathrm{H}), 4.39$ $(\mathrm{td}, J=8.0,5.6 \mathrm{~Hz}, 2 \mathrm{H}), 3.59(\mathrm{~s}, 6 \mathrm{H}), 2.99-2.82(\mathrm{~m}, 8 \mathrm{H}), 1.35-1.16$ $(\mathrm{m}, 8 \mathrm{H}) .{ }^{13} \mathrm{C}$ NMR $\left(100 \mathrm{MHz}, \mathrm{DMSO}-d_{6}\right) \delta 173.19,157.49,137.19$, $129.21,128.34,126.62,54.09,51.74,39.15,37.71,29.94,26.13$. HRMS (APCI) Calcd for $\mathrm{C}_{28} \mathrm{H}_{38} \mathrm{~N}_{4} \mathrm{O}_{6} 526.28$; found $549.26[\mathrm{M}+$ $\mathrm{Na}]^{+}$.

1S: Yield: $1.46 \mathrm{~g}, 92.3 \% .{ }^{1} \mathrm{H}$ NMR $\left(400 \mathrm{MHz}\right.$, DMSO- $\left.d_{6}\right) \delta 7.38-$ $7.07(\mathrm{~m}, 10 \mathrm{H}), 6.12(\mathrm{~d}, J=8.2 \mathrm{~Hz}, 2 \mathrm{H}), 6.06(\mathrm{t}, J=5.9 \mathrm{~Hz}, 2 \mathrm{H}), 4.40$ $(\mathrm{td}, J=8.0,5.6 \mathrm{~Hz}, 2 \mathrm{H}), 3.59(\mathrm{~s}, 6 \mathrm{H}), 2.93(\mathrm{~m}, J=17.1,8.9,7.9 \mathrm{~Hz}$, $8 \mathrm{H}), 1.42-1.09(\mathrm{~m}, 8 \mathrm{H}) .{ }^{13} \mathrm{C}$ NMR $\left(100 \mathrm{MHz}, \mathrm{DMSO}-d_{6}\right) \delta 173.20$, $157.52,137.20,129.22,128.35,126.64,54.11,51.76,39.17,37.73$, 29.96, 26.14. HRMS (APCI) Calcd for $\mathrm{C}_{28} \mathrm{H}_{38} \mathrm{~N}_{4} \mathrm{O}_{6}$ 526.28; found $549.26[\mathrm{M}+\mathrm{Na}]^{+}$.

Synthesis of Racemic Bis(urea) (1-rac). The rac-phenylalanine methyl ester $(1.11 \mathrm{~g}, 6.2 \mathrm{mmol})$ was dissolved in $60 \mathrm{~mL}$ chloroform and $2 \mathrm{~mL}$ of trimethylamine was added. A solution of 1,6disocyanatohexane $(500 \mu \mathrm{L}, 3.1 \mathrm{mmol})$ in chloroform $(40 \mathrm{~mL})$ was added dropwise under $\mathrm{N}_{2}$ atmosphere over a period of $1 \mathrm{~h}$. The resulting mixture was refluxed at $60{ }^{\circ} \mathrm{C}$ overnight, cooled to room temperature, and a similar reaction workup for $1 \mathbf{R}$ was followed to yield the desired product as a white powder. Yield: $1.57 \mathrm{~g}, 96.3 \% .{ }^{1} \mathrm{H}$ NMR (400 MHz, DMSO- $\left.d_{6}\right) \delta 7.33-7.12(\mathrm{~m}, 10 \mathrm{H}), 6.11(\mathrm{~d}, J=8.2$ $\mathrm{Hz}, 2 \mathrm{H}), 6.05(\mathrm{t}, J=5.7 \mathrm{~Hz}, 2 \mathrm{H}), 4.39(\mathrm{td}, J=8.1,5.6 \mathrm{~Hz}, 2 \mathrm{H}), 3.59$ $(\mathrm{s}, 6 \mathrm{H}), 3.00-2.82(\mathrm{~m}, 8 \mathrm{H}), 1.34-1.24(\mathrm{~m}, 4 \mathrm{H}), 1.24-1.15(\mathrm{~m}, 4 \mathrm{H})$. ${ }^{13} \mathrm{C}$ NMR (100 MHz, DMSO- $\left.d_{6}\right) \delta 173.22,157.55,137.21,129.24$, $128.37,126.66,54.13,51.78,39.18,37.74,29.97,26.15$. HRMS (APCI) Calcd for $\mathrm{C}_{28} \mathrm{H}_{38} \mathrm{~N}_{4} \mathrm{O}_{6} 526.28$; found $549.26[\mathrm{M}+\mathrm{Na}]^{+}$.

Gelation Details. Gelation Test. Ten milligrams of gelator was taken in a test tube and $1 \mathrm{~mL}$ of appropriate solvent was added. The mixed solution was heated until the compound was completely dissolved. The test tube was then sonicated and left undisturbed for gelation, and the gel formation was confirmed by inversion test.

Minimum Gel Concentration (MGC). Ten milligrams of the gelator $1 \mathrm{R}, 1 \mathrm{~S}$, or 1-rac was placed in a vial and $1 \mathrm{~mL}$ of solvent was added. The vial was heated until a clear solution was obtained. The solution was then sonicated and left to cool to room temperature for gelation. Additional solvent was added in portions and the gelation process was repeated until a small amount of solvent was left on top of the gel. The excess solvent was then decanted and MGC was calculated by weight. Similar experiments were performed for the $\mathbf{1 R}$ 
Scheme 2. Synthesis of 1R, 1S, and 1-rac Bis(urea) Compounds

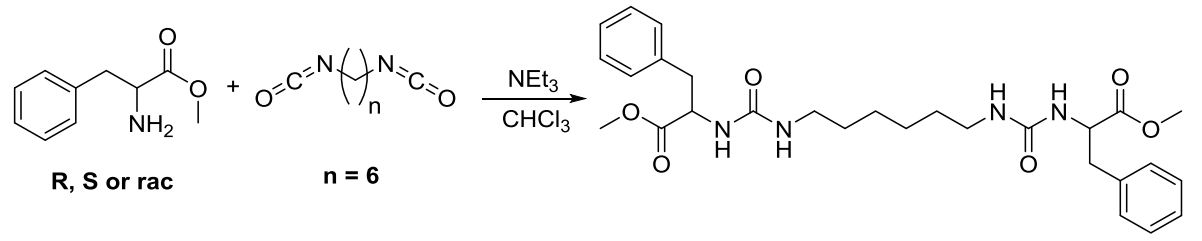

+1S mixed gel, which was prepared by mixing equal amounts of $1 \mathrm{R}$ and $1 S$.

$T_{\text {gel }}$ Experiment. Ten milligrams of the gelator (1R, 1S, or 1-rac) was taken in a standard $7 \mathrm{~mL}$ vial and $1 \mathrm{~mL}$ of appropriate solvent was added. The solution was heated and sonicated to dissolve the compound and allowed to stand undisturbed. After $24 \mathrm{~h}$, a small spherical glass ball $(92 \mathrm{mg})$ was placed on the top of the gel. The vial was placed over an oil bath equipped with a magnetic stirrer and a thermometer. The oil bath was gradually heated and the observation was noted. The temperature at which the glass ball touched the bottom of the vial was recorded as $T_{\text {gel }}$. Similar experiments were performed for the $1 R+1 S$ mixed gels by mixing $5 \mathrm{mg}$ of each $1 R$ and $1 S$.

Rheology. The rheological study was performed by using a TA Instruments Advanced Rheometer 2000 and toluene was selected as the gelling solvent. The gels of $\mathbf{1 R}, \mathbf{1 S}$, and 1-rac were prepared by heating $50 \mathrm{mg}$ of the corresponding gelator in $1 \mathrm{~mL}$ toluene and the resulting solutions were kept at room temperature without disturbing for $1 \mathrm{~h}$. The $\mathbf{1 R}+\mathbf{1 S}$ gel was prepared by mixing equal amounts of $1 \mathrm{R}$ and $1 \mathrm{~S}(25 \mathrm{mg}$ in $0.5 \mathrm{~mL}$ toluene), heating, and leaving at room temperature without disturbing for $1 \mathrm{~h}$. A stainless steel cone-plate geometry $\left(20 \mathrm{~mm}, 2^{\circ}\right.$ angle, truncation $\left.64 \mu \mathrm{m}\right)$ was used. Viscoelastic properties were evaluated by oscillatory measurements using a frequency sweep between 0.1 and $10 \mathrm{~Hz}$ within the linear viscoelasticity domain ( $0.05 \%$ deformation). Complex moduli $\left(G^{*}\right)$ and $\tan \delta$ were evaluated. Mechanical properties were determined by uniaxial compression measurements using a TA HD Plus Texture Analyzer (Stable Micro Systems, UK) with a stainless steel $0.5 \mathrm{~mm}$ probe. The probe penetrated $80 \%$ of the initial height using a crosshead speed of $1 \mathrm{~mm} / \mathrm{s}$.

Scanning Electron Microscopy (SEM). Twenty milligrams of the gelator $(1 \mathrm{R}, 1 \mathrm{~S}$, or 1-rac) was dissolved in $1 \mathrm{~mL}$ of toluene/ethyl acetate by heating and sonicating. The solution was allowed to stand undisturbed to form the gel. After $24 \mathrm{~h}$, it was filtered through a filter paper and the residue was dried in air. The $\mathbf{1 R + 1 S}$ xerogel was prepared by same procedure using the gel obtained by mixing equal amounts of $1 \mathrm{R}$ and $1 \mathrm{~S}$. The xerogels were gold coated and placed on a Leo Supra 25 microscope for scanning electron microscopy and the morphologies of the dried gels were examined by SEM. The EtOH/ water xerogels were lightly dusted onto double-sided carbon tape and then coated with a $30 \mathrm{~nm}$ layer of platinum using a Leica EM ACE600, where the thickness was monitored using a film thickness monitor. The SEM imaging for EtOH/water gels were undertaken on a NanoSEM 230 fitted with a through lens detector at an operating voltage of $5 \mathrm{kV}$, with a working distance between 4.9 and $5.7 \mathrm{~mm}$.

Atomic Force Microscopy (AFM). Gels of 1R, 1S (0.7 wt \%), 1$\operatorname{rac}(0.15 \mathrm{wt} \%)$, and $1 \mathbf{R}+\mathbf{1 S}(0.3 \mathrm{wt} \%)$ were dispersed in appropriate solvent (toluene or $\mathrm{EtOH} /$ water), heated to dissolve, and cooled to form gels within $5 \mathrm{~min}$. The solutions were diluted $5 \times(100+400 \mu \mathrm{L}$ solvent) and $10 \times(100+900 \mu \mathrm{L}$ solvent $)$. One drop of the organogel in its solution phase was cast onto a mica substrate, followed by spreading of the drop over the mica using a glass slide, with the excess liquid wicked away using capillary action. The samples were left to dry overnight before imaging, which was undertaken on a Bruker Mulitmode 8 Atomic Force Microscope in Scanasyst Air (PeakForce Tapping) mode, which is based upon tapping mode AFM, but the imaging parameters are constantly optimized through the force curves that are collected, preventing damage to soft samples. Bruker Scanasyst-Air probes were used, with a spring constant of $0.4-0.8$ $\mathrm{nm}$ and a tip radius of $2 \mathrm{~nm}$.
Circular Dichroism (CD). The data were collected using a ChirascanPlus CD spectrometer (Applied Photophysics, UK) scanning between wavelengths of 180 and $500 \mathrm{~nm}$ with a bandwidth of $1 \mathrm{~nm}, 0.6 \mathrm{~s}$ per point, and step of $1 \mathrm{~nm}$. The gels of $1 \mathrm{R}, 1 \mathrm{~S}, 1-\mathrm{rac}$, and $(\mathbf{R}+1 \mathbf{S}$ were prepared at their minimum gel concentration in $\mathrm{EtOH} /$ water $(1: 1 \mathrm{v} / \mathrm{v})$. After $24 \mathrm{~h}$, the gel was dispersed in EtOH/ water $(1: 1 \mathrm{v} / \mathrm{v})$ to obtain various concentrations $(0.005,0.025$, and $0.05 \mathrm{wt} \%)$ for $\mathrm{CD}$ experiments. The $\mathrm{CD}$ experiments in the solution state were performed by dissolving $2.5 \mathrm{mg}$ of the gelator (either $1 \mathrm{R}$, 1S, 1-rac, or $1 \mathrm{R}+\mathbf{1 S}$ ) in $10 \mathrm{~mL}$ of absolute ethanol.

Optical Rotation Measurements (OD). The OD experiments for both enantiomers, the racemic mixture, and the mixed gel (at 50/ $50 \mathrm{wt} / \mathrm{wt}$ ) were carried out at $589 \mathrm{~nm}$, on an Autopol V from Rudolph research analytical, in both a gelling solvent (toluene) and a nongelling solvent (2-butanol). Due to the opaque nature of the gel, the concentration was kept under the minimum gel concentration.

NMR Experiments. The solution state ${ }^{1} \mathrm{H}$ and ${ }^{13} \mathrm{C}$ NMR spectra were recorded on Bruker Advance 400 spectrometer $\left({ }^{1} \mathrm{H}\right.$ NMR: 400 $\mathrm{MHz},{ }^{13} \mathrm{C}$ NMR: $100 \mathrm{MHz}$ ). The solid-state NMR spectra were recorded on Bruker Avance III $700 \mathrm{MHz}$ spectrometer on xerogels of $1 \mathrm{R}, 1 \mathrm{~S}, 1-\mathrm{rac}$, and $1 \mathrm{R}+1 \mathrm{~S}$ in toluene at $1 \mathrm{wt} \%$.

\section{RESULTS AND DISCUSSION}

We have selected the bis(urea) moiety as a hydrogen-bonding backbone, which has been extensively used as a supramolecular synthon for the self-assembly of gelators in LMWGs with tunable properties. ${ }^{71-76}$ Compounds based on bis(urea) ligands form a $\alpha$-urea tape structure, which will result in a one-dimensional tape-like network (fibrils), and these fibrils aggregate to form an interconnected, entangled 3-D framework capable of immobilizing solvent molecules, thereby inducing gelation in small molecules. ${ }^{77-81}$ Enantiopure $R-R(\mathbf{1 R})$ and $S-S$ (1S) bis(urea) compounds based on amino acid derivatives were synthesized by reacting 1,6-diisocyanatohexane and the corresponding methyl ester protected amino acid hydrochloride in chloroform. ${ }^{81-83}$ The racemate bis(urea) compound (1-rac), which is a statistical mixture of $R-S, R-R$, and $S-S$ (see the Supporting Information), was synthesized by reacting racemate phenylalanine methyl ester with 1,6diisocyanatohexane in chloroform (Scheme 2). The gelation properties of these compounds were tested in a series of solvents.

Gelation Experiments. The initial screening was performed in a series of solvents with 1 wt $\%$ of the compound. In a typical experiment, the compounds were heated and sonicated in a particular solvent to get a clear solution, cooled to room temperature, and the gel formation was confirmed by inversion test (Figure 1). All the three bis(urea) compounds (1R, 1S, and 1-rac) formed gels in 1,2dichloroethane, benzene, toluene, $o$-xylene, $m$-xylene, $p$-xylene, chlorobenzene, ethyl acetate, 2-butanone, and nitrobenzene. It is quite interesting that all the three forms (both enantiomeric and racemate) show gelation for a wide range of solvents. Generally, selective gelation is observed with either the enantiomers or racemate, ${ }^{46,53,54,56,84}$ but gel formation of both enantiomers and racemate is rare. ${ }^{56,57,85,86}$ The selective 

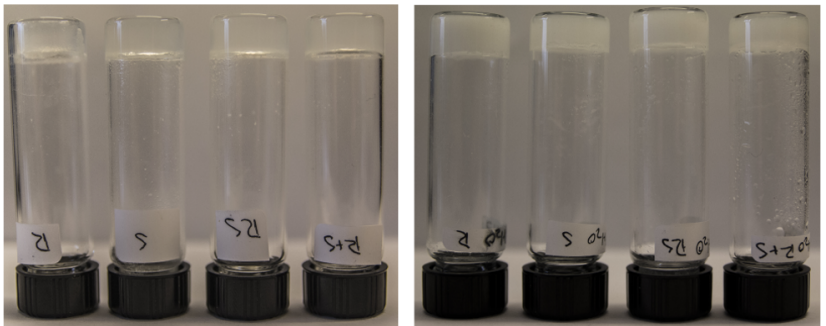

Figure 1. Gel images (left) in toluene and (right) $\mathrm{EtOH} /$ water (50\% $\mathrm{v} / \mathrm{v})$.

gelation of 1-rac at 1 wt \% was observed in cyclohexanone and mesitylene (Table S1, see the Supporting Information). The occurrence of partial gels prompted us to check the gelation of the compounds at higher concentrations, and the gels were obtained at higher wt $\%$ for $\mathbf{1 R}$ and $\mathbf{1 S}$ in mesitylene ( $2 \mathrm{wt} \%)$. The gels were formed at $2 \mathrm{w} \%$ for the racemate 1-rac in isopropanol, 2-pentanol, and $n$-pentanol and in ethanol at $3 \mathrm{wt}$ $\%$. We have also checked the gelation properties in aqueous solution by using $50 \%(\mathrm{v} / \mathrm{v})$ of water and a co-solvent (either methanol, ethanol, DMA, DMF, and DMSO) to dissolve the compounds. The hydrogels were obtained at $1 \mathrm{wt} \%$ for most of the cases except for 1-rac in DMF/water and DMSO/water, where gelation occurred at $2 \mathrm{wt} \%$.

The minimum gel concentration of the gelators were evaluated in solvents such as ethyl acetate, 2-butanone, toluene, chlorobenzene, xylenes (ortho-, meta-, and para-), and nitrobenzene (Table S2, see the Supporting Information). Interestingly, 1-rac compounds formed gels at lower concentration compared to $1 \mathrm{R}$ and $1 \mathrm{~S}$. The 1-rac gels formed in toluene, chlorobenzene, and xylenes (ortho-, meta-, and para-) can be classified as supergelators. Specifically, less than half the concentration was required to form the gels for 1-rac gels compared to enantiomerically pure gels, indicating that the presence of both isomers increases the gelling ability. This may be attributed to the $\pi-\pi$ interaction between the solvents and the gelator molecules in the 3-D network within which the solvent molecules are entrapped. Furthermore, the $\alpha$-sheet-like structure of the urea network could be preserved due to the absence of the strong hydrogen-bonding moieties. These results clearly indicate that both $1 \mathrm{R}$ and $1 \mathrm{~S}$ self-assemble to form a strong network in the racemate form 1-rac. This leads to an interesting question, what happens when two enantiomers are mixed? Will $1 \mathrm{R}$ and $1 S$ undergo self-sorting or co-assembly to form conglomerate or racemate? This prompted us to evaluate the gelation property of mixed enantiomers by mixing equal amounts of $1 \mathrm{R}$ and $1 \mathrm{~S}$ in a series of solvents at 1 wt $\%$ resulting in mixed gels. The mixed gel turned out to be an excellent multicomponent gel, and the gels were formed in 23 solvents. Analyzing the gelation results revealed that $\mathbf{1 R}+\mathbf{1 S}$ formed gel at $1 \mathrm{wt} \%$ in solvents such as acetonitrile, tetrahydrofuran, acetone, 2-butanol, $n$-butanol, and 1,4-dioxane and $2 \mathrm{wt} \%$ in $n$-propanol, whereas $1 \mathrm{R}, 1 \mathrm{~S}$, and 1-rac did not form gel in these solvents (Table S1, see the Supporting Information). The experiments performed on mixed gels prepared by mixing equimolar solutions of $\mathbf{1 R}$ and $1 S$ resulted in similar gelation properties.

Gel Strength. The thermal stability of the gel network was evaluated using gel-to-solution transition temperature test $\left(T_{\text {gel }}\right)$. To compare the gel strength, we selected solvents such as toluene, ethyl acetate, xylenes (ortho-, meta-, and para-), 2butanone, chlorobenzene, and $\mathrm{EtOH} /$ water $(50 \% \mathrm{v} / \mathrm{v})$ and the gel concentration was fixed at 1 wt $\%$. The analysis of the results revealed that $T_{\text {gel }}$ of $1 \mathrm{R}$ in toluene, m-xylene, and $p$ xylene is higher compared to $\mathbf{1 S}$ and 1-rac gels (Table 1). In

Table 1. Gel-Sol Transition Temperature $\left({ }^{\circ} \mathrm{C}\right)$ of the Enantiomers, Racemate, and Mixed Gels at 1 wt \%

\begin{tabular}{lcccr}
\multicolumn{1}{c}{ solvent } & $1 \mathrm{R}$ & $1 \mathrm{~S}$ & 1 -rac & $1 \mathrm{R}+1 \mathrm{~S}$ \\
toluene & 91.0 & 86.5 & 85.0 & 106.5 \\
ethyl acetate & 55.0 & 54.5 & 61.0 & 73.5 \\
$p$-xylene & 94.0 & 91.0 & 98.0 & 102.0 \\
$m$-xylene & 99.0 & 95.0 & 97.0 & 102.0 \\
$o$-xylene & 92.0 & 91.0 & 90.0 & 99.0 \\
2-butanone & 38.0 & 37.5 & 40.0 & 55.5 \\
chlorobenzene & 73.0 & 70.5 & 75.5 & 90.5 \\
EtOH/water & 51.5 & 44.5 & 52.5 & 55.5 \\
\hline
\end{tabular}

other cases, the 1-rac gel displayed the highest $T_{\text {gel }}$ value, indicating a thermally stronger network, whereas $1 \mathrm{~S}$ showed similar or lower values than $\mathbf{1 R}$. Interestingly, there is a distinct difference in $1 \mathrm{R}+1 \mathrm{~S}$ mixture $T_{\mathrm{ge}}$, which is higher than that of pure enantiomers and racemate in all cases (Table 1). A difference of $10-20{ }^{\circ} \mathrm{C}$ was observed for toluene, ethyl acetate, and 2-butanone. This clearly indicates that the 3-D network in the enantiomers and the mixed gels is different. This was confirmed by variable temperature rheology experiments in toluene (Figure S1, see the Supporting Information). We have also compared the $T_{\text {gel }}$ of the hydrogels obtained from EtOH/ water $(1: 1, \mathrm{v} / \mathrm{v})$, and $\mathbf{1 R + 1 S}$ gels showed greater thermal stability compared to the enantiomers and the racemate gels. The enhanced thermal stability of the mixed gel $(\mathbf{1}+\mathbf{1 S})$ may be attributed to the self-assembly of these components into a new or mixed network as compared to the enantiomer and racemate fibrils. The $T_{\text {gel }}$ experiments performed on $1 \mathrm{wt} \%$ of mixed gels by varying the concentration of both $1 \mathrm{R}$ and $1 \mathrm{~S}$ revealed that the gel formation of $1 R+1 S$ depends on $1 R$ and 1S concentrations, respectively (Figure 2 ).

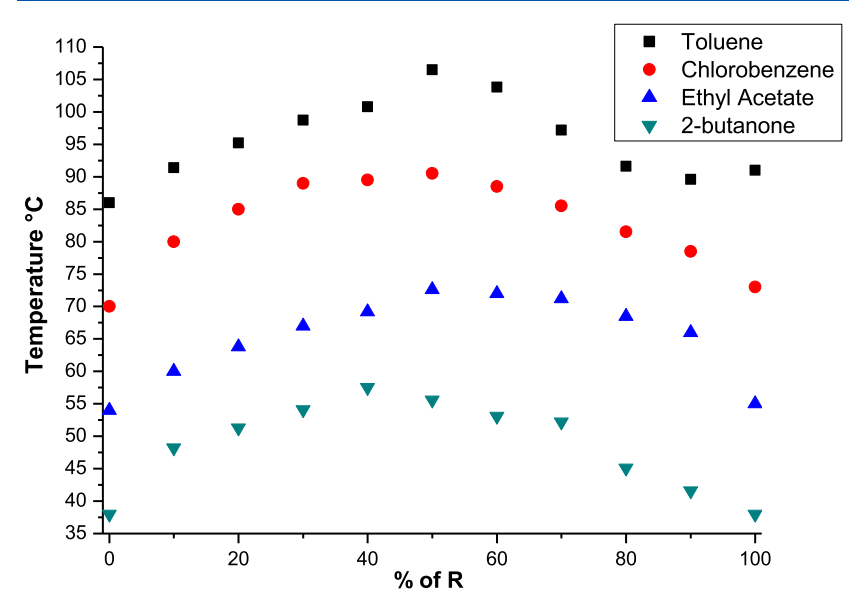

Figure 2. $T_{\text {gel }}$ of $1 \mathrm{R}+1 \mathrm{~S}$ gels by varying the concentration of both $1 \mathrm{~S}$ and $1 \mathrm{R}$ in toluene, ethyl acetate chlorobenzene, and 2-butanone.

Rheology. Rheology was used to evaluate the structural characteristics of supramolecular gels, which enables us to elucidate the information regarding factors controlling the gelation, gel strength, and the solid-like properties of pure gels. For example, Adams and co-workers reported that the combination of self-sorted LMWGs and photoresponsive 
gelators offers the possibility of spatially controlling the rheological properties of LMWG. ${ }^{45}$ We performed frequency sweep experiments to compare the relative gel behavior of $\mathbf{1 R}$, $1 S$, 1-rac, and $1 R+1 S$ in toluene at 5 wt \%. Elastic $\left(G^{\prime}\right)$ and viscous $\left(G^{\prime \prime}\right)$ moduli were evaluated, as well as the complex modulus $\left(G^{*}=\sqrt{\left.G^{\prime 2}+G^{\prime \prime 2}\right)}\right.$ and $\tan \delta\left(G^{\prime \prime} / G^{\prime}\right)$.

It is worth mentioning that a strain sweep was also carried out to determine the linear viscoelastic region. This ensured that the systems did not undergo an irreversible deformation during the experiments and the original structure of the organogels can be evaluated. All the organogels showed a gellike behavior with no frequency dependence (Figure 3). The

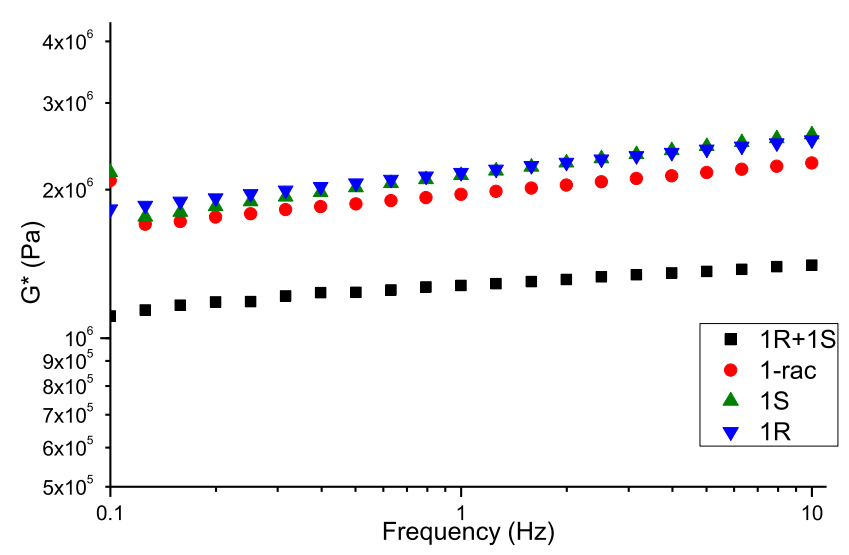

Figure 3. Complex modulus $G^{*}$ for gels produced with 1R, 1S, 1-rac, and $1 R+1 S$ in toluene at 5 wt \%.

1R, 1S, and 1-rac gels exhibited very similar $G^{*}$ behavior. However, the $\mathbf{1 R + 1 S}$ gel had a slightly lower complex modulus $\left(G^{*}\right)$ value, indicating the presence of a weak fibrous network in comparison to other gels. It should be noted that the $G^{\prime}$ values of $1 R+1 S$ were not so different from those of other gels, but the viscous contribution $\left(G^{\prime \prime}\right)$ was higher for $1 R, 1 S$, and 1-rac systems, leading to higher values of $G^{*}$. Indeed, $\tan \delta$ results presented lower values for the $1 R+1 S$ system, whereas the other gels remained very close to each other (Figure S2, see the Supporting Information). The lower $\tan \delta$ value indicates a prevailing elastic modulus $\left(G^{\prime}\right)$, i.e., more solid characteristic, which will enable the network to withstand higher applied forces without irreversible deformation. The mechanical strength of all the gels was compared by evaluating the force required to penetrate a certain distance through a gel, plotting force vs distance (Figure 4). Unlike rheological analysis, mechanical properties measure high and irreversible deformation, complementing the rheological results, which are performed at small deformations. These results clearly indicate that 1R, 1S, and 1-rac showed similar behavior with maximum forces with same magnitude. On the other hand, a higher maximum force was observed for the mixed gels $(\mathbf{1 R}+\mathbf{1 S})$. Moreover, a larger area under the curve also means a stronger structure, which was observed for $1 \mathrm{R}+\mathbf{1 S}$, indicating that this gel was stronger in comparison to the other systems. Mechanical results corroborated rheological tests, showing that $\mathbf{1 R + 1 S}$ presented more solid character with higher resistance to applied forces.

Gel Morphology. The morphologies of all the gels were analyzed by scanning electron microscopy (SEM). All the gels were prepared at $2 \mathrm{wt} \%$ in toluene and ethyl acetate, then filtered, and dried under a fume hood for 2-3 days. A small

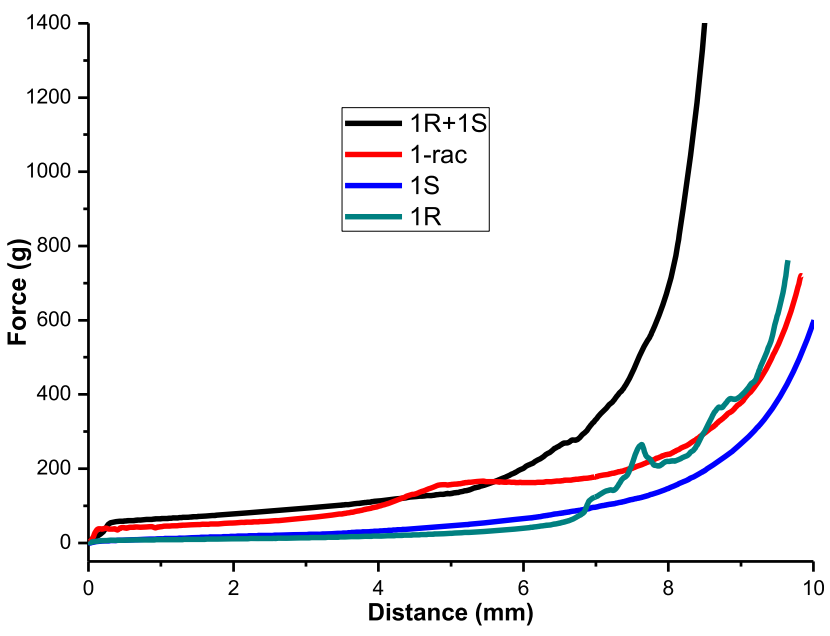

Figure 4. Comparison of mechanical strength for gels 1R, 1S, 1-rac, and $1 R+1 S$ in toluene at 5 wt $\%$.

portion of the dried gel was placed on a pin mount with graphite planchets on top and coated with gold for $3 \mathrm{~min}$. The SEM images revealed that all xerogels display typical fibrous and helical network (Figures 5 and 6). The SEM images of the xerogels from ethyl acetate showed that $1 \mathrm{R}$ and $1 \mathrm{~S}$ form a helical fibrous network (Figure S3). The individual fibrils form
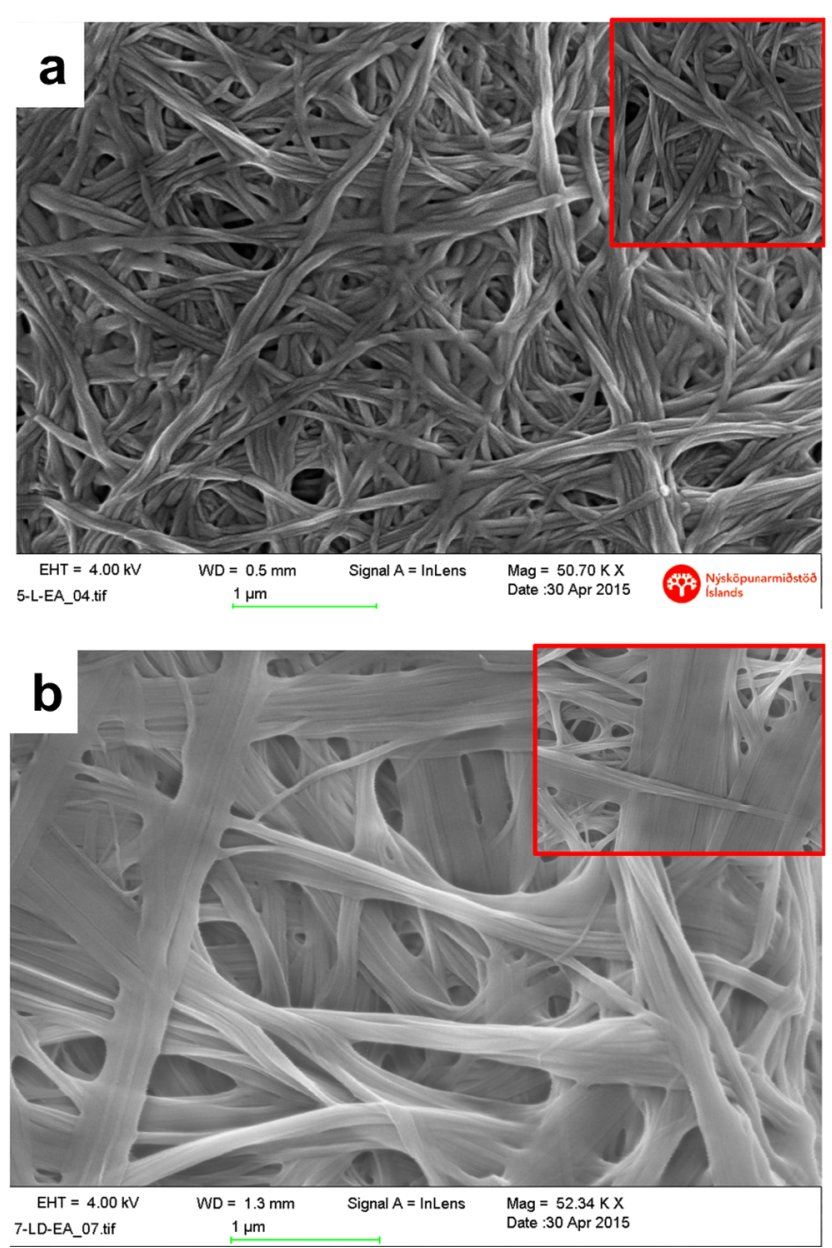

Figure 5. SEM images of (a) 1S and (b) 1-rac xerogels in ethyl acetate, inset shows the magnified images. 


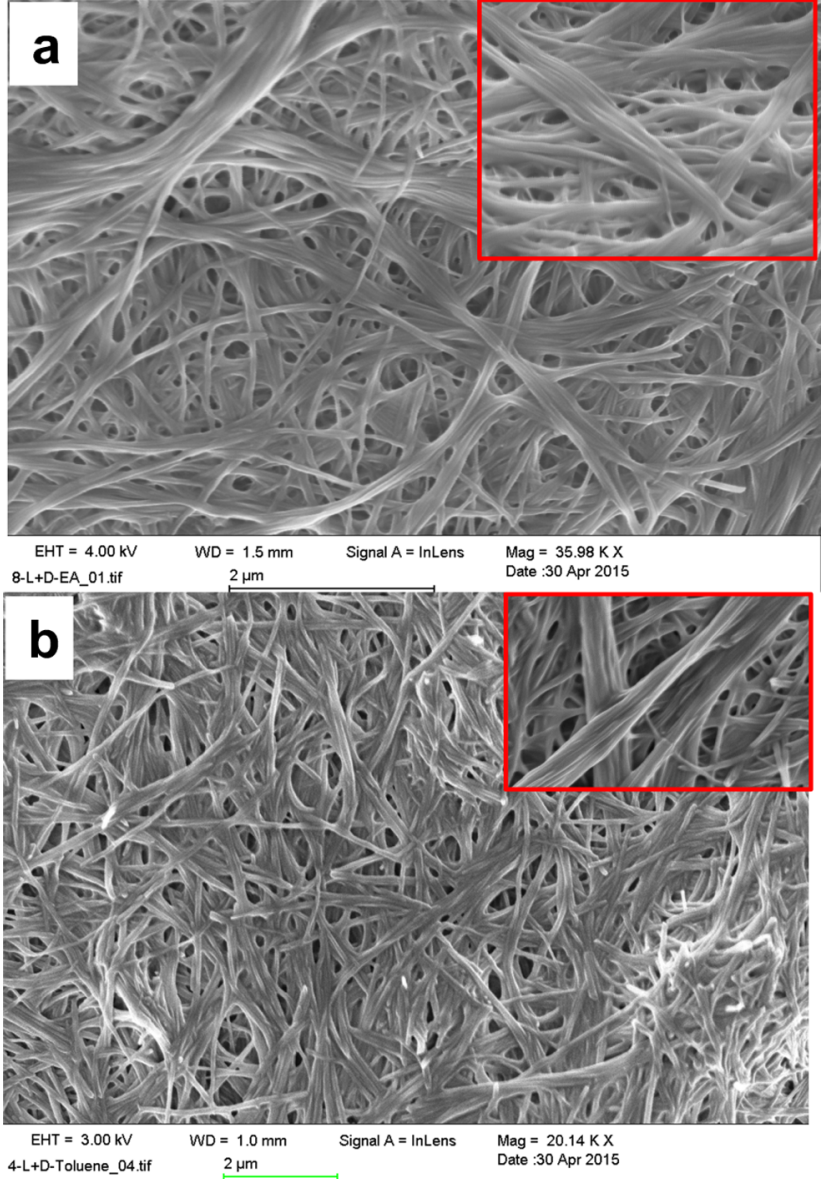

Figure 6. SEM images of $\mathbf{1 R + 1 S}$ xerogels in (a) ethyl acetate and (b) toluene, inset shows the twisted-tape morphology.

helical fibrous aggregates with varying dimensions, and the thickness of each helical fiber varied from 25 to $40 \mathrm{~nm}$. The larger bundles of $100-150 \mathrm{~nm}$ are formed by wrapping individual fibers around each other in a helical manner, resulting in physically entangled networks; this type of twisting is often observed in chiral compounds. ${ }^{84,87,88}$ The helicity of single fibers for $1 \mathrm{R}$ and $1 \mathrm{~S}$ clearly indicates that molecular chirality had been successfully transferred to the hierarchical aggregates (Figure 5a). The morphology of racemate xerogel 1-rac showed tape-like fibers, which is different from that of its enantiomers (Figure 5b). The thickness of each fiber varied from 50 to $200 \mathrm{~nm}$, with few fibrils wrapped around each other. Interestingly, a twisted tape-like architecture was observed in $\mathbf{1}+\mathbf{1 S}$ with bundles of varying dimension from 50 to $200 \mathrm{~nm}$, indicating the presence of both enantiomers and racemate (Figure 6a). The SEM of xerogels obtained from toluene showed similar morphologies, both $1 \mathrm{R}$ and $1 \mathrm{~S}$ form helical fibrous network with a thickness of 30-70 nm (Figure S4, see the Supporting Information). These small fibers merge with each other to form a thicker helix of diameter 150-200 $\mathrm{nm}$.

Xerogels of 1-rac from toluene shows similar tape-like morphology (Figure S5, see the Supporting Information). The 1R+1S xerogel displayed twisted-tape morphology similar to ethyl acetate gels and the diameter of the fibers was found to be $100-250 \mathrm{~nm}$. The SEM analysis of the xerogels obtained from $\mathrm{EtOH} /$ water $(50 \% \mathrm{v} / \mathrm{v})$ also support the presence of mixed network in $\mathbf{1 R + 1 S}$ gels (Figure S6, see the Supporting
Information). The presence of two types of networks in the SEM images corroborate well with the rheology results. In mixed networks, elastic character of the gel network was increased due to higher entanglement, which is evident from the rheology results of $\mathbf{1 R + 1 S}$ compared to other gels.

Atomic Force Microscopy (AFM). The morphology of the gel fibers was further analyzed by AFM studies. The gels were made by dissolving $1 \mathbf{R}(0.7 \mathrm{wt} \%), \mathbf{1 S}(0.7 \mathrm{wt} \%)$, and 1rac $(0.15 \mathrm{wt} \%)$ in toluene. The $\mathbf{1 R}+\mathbf{1 S}$ gel was prepared by dissolving individual $\mathbf{1 R}$ and $\mathbf{1 S}$ in toluene $(0.3 \mathrm{wt} \%)$ and then heating. All these gels were further dispersed in toluene (10X), dropped on a plate, dried at room temperature, and analyzed by AFM. Analysis of the AFM images of $1 R$ and $1 S$ revealed that both enantiomers have a twisted single helix with a uniform right- and left-handed morphology, respectively (Figure 7). However, a tape-like morphology was observed for 1-rac, which clearly indicated that the helicity was canceled due to the co-assembly of both $\mathbf{R}$ and $\mathbf{S}$ fibrils (Figure 8).
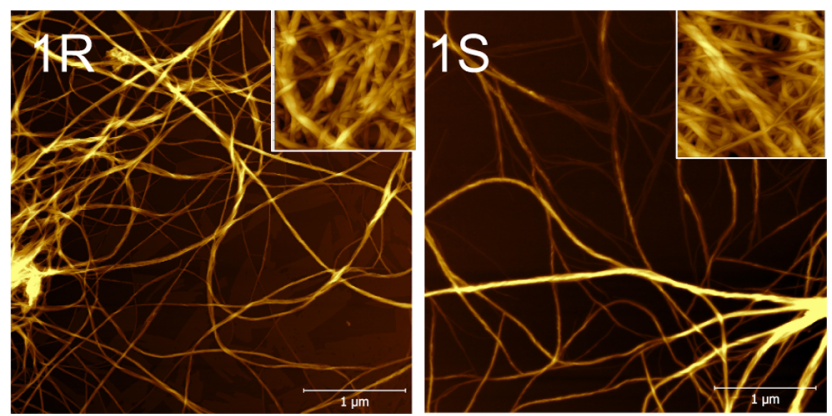

Figure 7. AFM images of $1 \mathrm{R}$ and $1 \mathrm{~S}$ showing the left- and righthanded helical fibers; inset shows the magnified images.
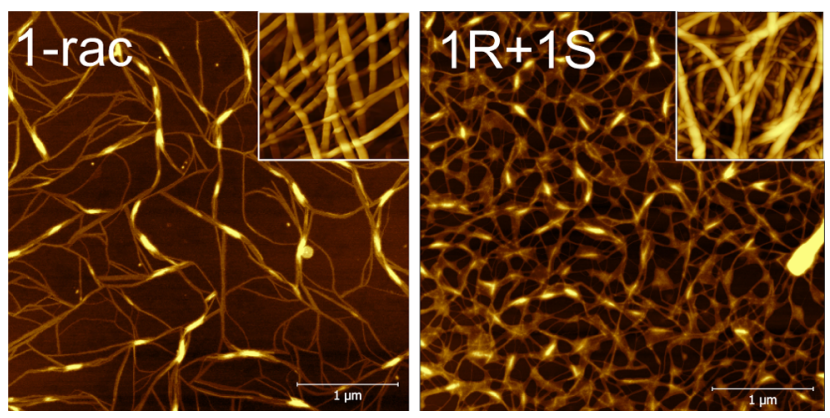

Figure 8. AFM images showing tape-like architecture of 1-rac and a mixture of tape and helical morphology of $1 \mathrm{R}+\mathbf{1 S}$; inset shows the magnified images.

Interestingly, the mixed gel $\mathbf{1 R + 1 S}$ showed both twisted and tape-like morphology. This may be attributed to the selfsorting and co-assembly of $\mathbf{1 R}$ and $\mathbf{1 S}$ fibrils when they are mixed and heated together. Similar morphologies were observed for $\mathrm{EtOH} /$ water $(50 \% \mathrm{v} / \mathrm{v})$ gels and the AFM images of $1 \mathrm{R}$ and $1 \mathrm{~S}$ showed helical fibers, a tape-like morphology for 1-rac, and both twisted and tape-like morphology for $\mathbf{1 R + 1 S}$ (Figures S9 and S10, see the Supporting Information).

Circular Dichroism (CD). The sensitivity of CD to chiral perturbations will provide information about the molecular chirality and the difference between $\mathrm{CD}$ signals of selfassembled and isolated state will enable us to elucidate the structural information of the assembled hierarchical struc- 
ture. ${ }^{89}$ Although we screened a series of solvents, which are capable of forming gels with 1R, 1S, and 1-rac, these solvents were discarded due to background absorption. We have selected $\mathrm{EtOH} /$ water mixture for our studies, which showed an absorption cutoff at around 190-200 nm. The CD experiments were performed at various concentrations in dispersed gel state and weak signals were observed below $0.005 \mathrm{wt} \%$ for all gelators. On the other hand, increasing the concentration above $0.05 \mathrm{wt} \%$ resulted in saturation of CD signals. Thus, we selected $0.025 \mathrm{wt} \%$ as the optimum concentration for the enantiomers, racemate, and mixed gels (Figure 9a). The CD
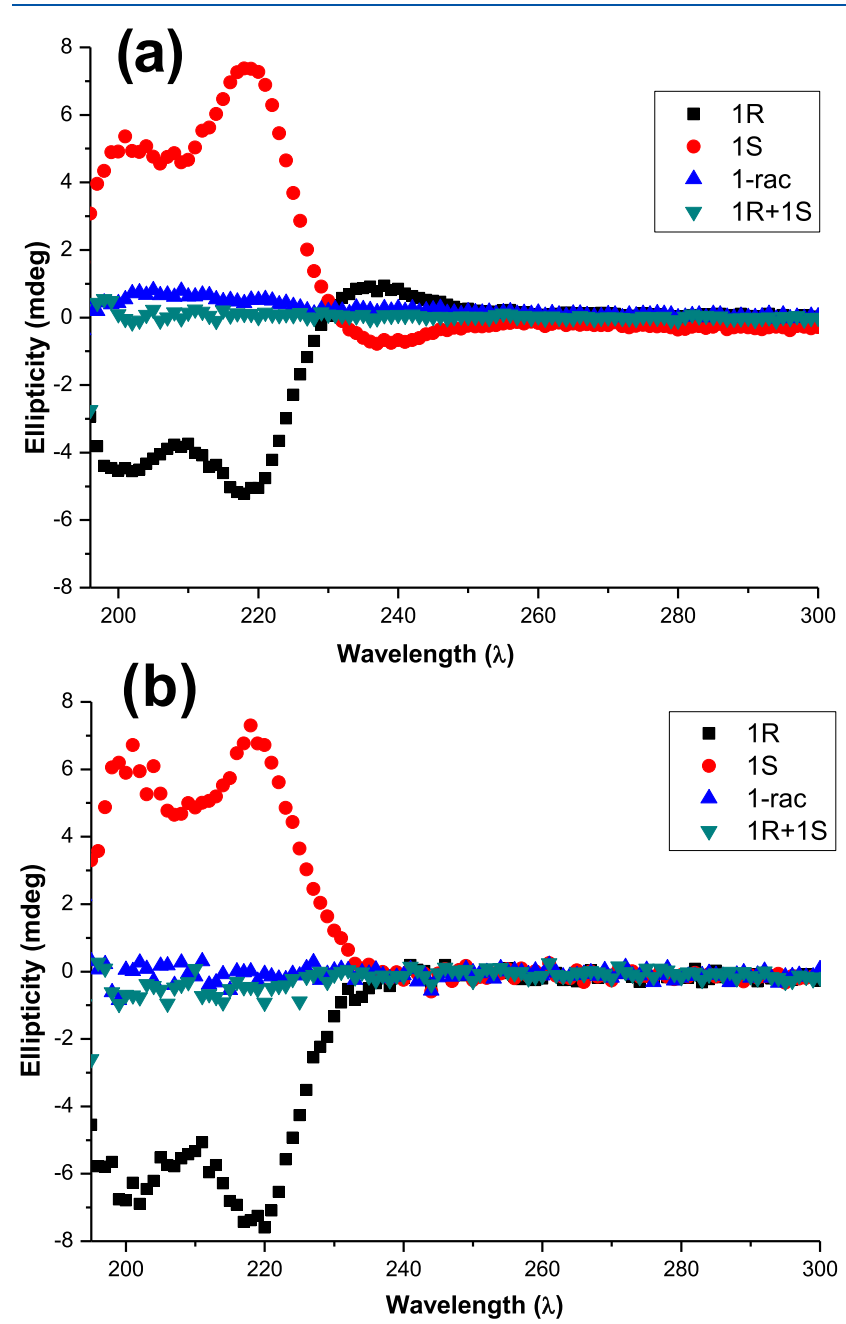

Figure 9. CD spectra of 1R, 1S, 1-rac, and $1 \mathrm{R}+1 \mathrm{~S}$ in dispersed gel state (a) and in solution state (b).

signal maxima observed at 200 and $220 \mathrm{~nm}$ for $1 \mathrm{~S}$ may be attributed to the existence of $\pi-\pi$ stacking interactions from the aromatic units. ${ }^{90,91}$ The $\mathrm{CD}$ spectrum of $\mathbf{1 R}$ showed negative signals, which is similar to the mirror image of the $\mathrm{CD}$ signal of $1 \mathrm{~S}$. The gels of $1-\mathbf{r a c}$ and $\mathbf{1 R}+\mathbf{1 S}(50 \% \mathrm{v} / \mathrm{v})$ displayed a linear CD signal, indicating the presence of both enantiomers in the gel state. To get an insight into the self-assembly process, the $\mathrm{CD}$ of these compounds in the solution state was also analyzed (Figure $9 \mathrm{~b}$ ) and compared to the gel state CD, which indicated the formation of self-assembled networks in the gel state. The small peak at $240 \mathrm{~nm}$ observed in the gel state $\mathrm{CD}$ is likely due to the stacking of the aromatic phenylalanine groups within the gel. We have also performed the $\mathrm{CD}$ experiments of $\mathbf{1 R + 1 S}$ by varying the concentration of $1 \mathrm{R}$ and $1 \mathrm{~S}$. The CD spectrum of $1 \mathrm{R}+\mathbf{1 S}(75 \% 1 \mathrm{R} \mathrm{v} / \mathrm{v})$ mixture displayed negative maxima, indicating the presence of excess 1R (Figure S11, see the Supporting Information). Similarly, the experiments with $\mathbf{1 R}+\mathbf{1 S}(25 \% \mathbf{1 R} \mathrm{v} / \mathrm{v})$ displayed positive maxima.

We have also performed optical rotation measurements for 1R, 1S, 1-rac, and $1 \mathrm{R}+\mathbf{1 S}$ at $589 \mathrm{~nm}$ in a solution (2-butanol) and a gelling solvent (toluene) at concentrations below the minimum gel concentrations (Table S4, see the Supporting Information). The observations were similar to that of the CD experiments.

Nuclear Magnetic Resonance (NMR) Spectroscopy. The self-assembly of $1 R, 1 S, 1-r a c$, and $1 R+1 S$ was studied by NMR spectroscopy. The ${ }^{1} \mathrm{H}$ and ${ }^{13} \mathrm{C}$ NMR of $1 R, 1 S, 1-$ rac, and $1 R+1 S$ in the solution state was recorded in DMSO- $d_{6}$ and similar NMR spectra suggest that enantiomers, racemate, and mixed enantiomers have identical environment in the solution state (Figures S12 and S13, see the Supporting Information). To analyze their self-assembly in the gel state, solid-state NMR was performed on the xerogels of $1 R, 1 S, 1-r a c$, and $1 R+1 S$ by filtering $1 \mathrm{wt} \%$ gels, followed by drying, and compared with the solution-state NMR (Figure 10).

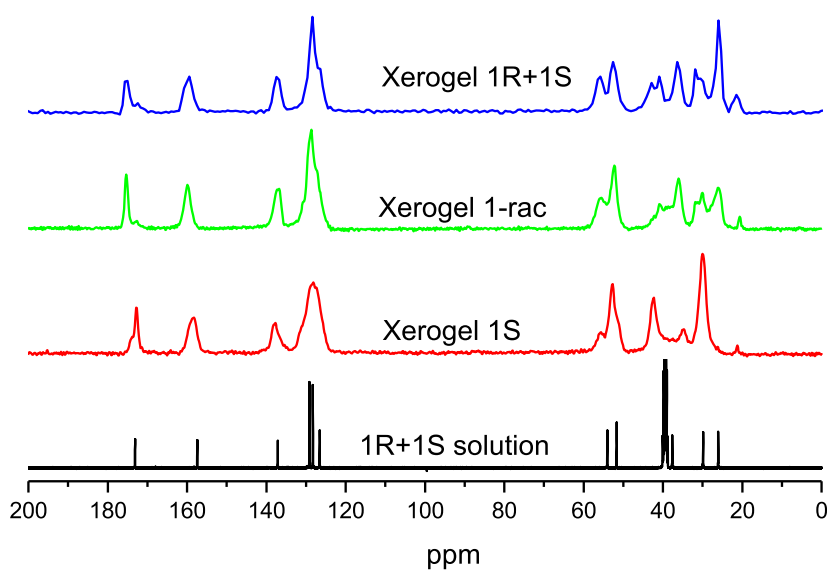

Figure 10. Comparison of the solid-state and solution-state ${ }^{13} \mathrm{C}$ NMR of $1 R, 1 S$, 1-rac, and $1 R+1 S$.

Analysis of the ${ }^{13} \mathrm{C}$ NMR of the four samples revealed that the solid-state packing of the xerogels is not identical (Figure S14, see the Supporting Information), which may be attributed to the difference in the molecular self-assembly. Generally, the morphology and molecular arrangement of original gels are translated to the xerogels, but in some cases, the removal of solvent may result in artefacts due to dissolution and recrystallization, changes in morphology, or polymorphic phase transition. 9 The NMR spectra of enantiopure $\mathbf{1 R}$ and IS were identical due to the similar three-dimensional packing in these structures because of their mirror image. This observation corroborates nicely with the SEM and AFM images, where a helical fibrous network was observed for $1 \mathbf{R}$ and 1S. However, the peak at $\delta=42.5 \mathrm{ppm}$ was missing in racemic 1-rac, but more peaks were observed at $\delta=26.0,31.8$, 36.3 , and $40.9 \mathrm{ppm}$ (Figure 11). Thus, the self-assembly in the racemate is different from its enantiomers and evident from the tape-like fibers in the SEM and AFM images. The packing mode of $1 R+1 S$ was analyzed by comparing the NMR spectra of $\mathbf{1 R}, \mathbf{1 S}$, and $\mathbf{1 - r a c}$ with that of $\mathbf{1 R + 1 S}$ (Figure 11). It is clear 


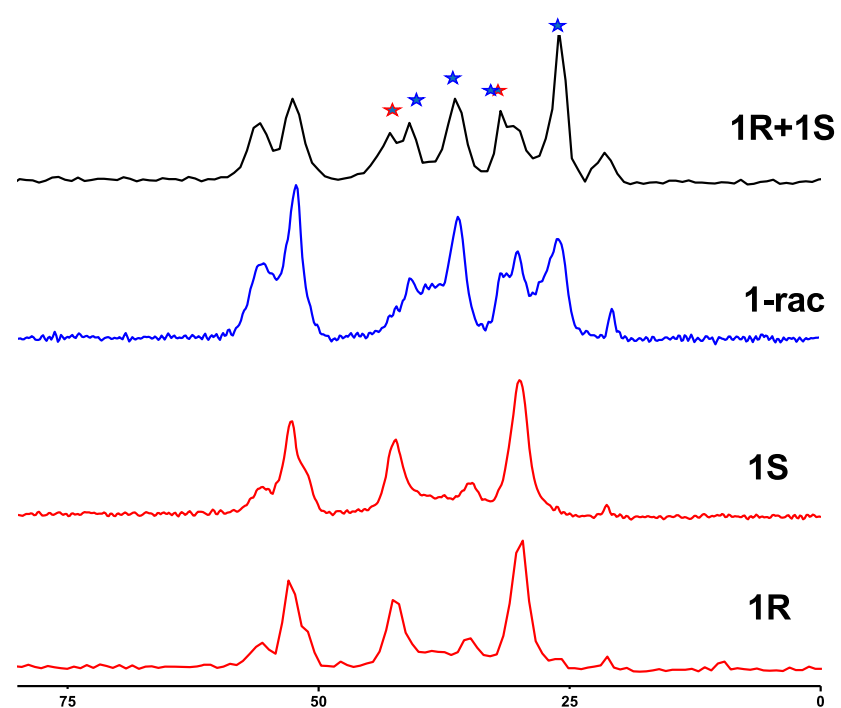

Figure 11. Comparison of the solid-state ${ }^{13} \mathrm{C}$ NMR of 1R, 1S, 1-rac, and $1 R+1 S$ for the aliphatic region showing the mixed network in solid state for $1 \mathbf{R}+\mathbf{1 S}$ (*indicates the corresponding peaks in enantiomers and racemate).

from the spectra that $1 \mathrm{R}+\mathbf{1 S}$ network is a mixture of fibers from both enantiomers and the racemate, which indicates the presence of both self-sorted and co-assembled fibers in $\mathbf{1 R}+\mathbf{1 S}$.

\section{CONCLUSIONS}

We have successfully synthesized the enantiopure (1R) and racemic (1-rac) forms of bis(urea)-based phenylalanine methyl ester. The known enantiomeric form (1S) was also synthesized and all the isomers were found to be excellent gelators capable of gelling a wide range of solvents. Multicomponent gels based on enantiomers were prepared by mixing equal amounts of pure enantiomers as well as varying individual enantiomer concentrations. The gels were characterized using standard gelation techniques and the morphology was analyzed by SEM, AFM, and solid state NMR. The mixed gel displayed a higher thermal and mechanical strength compared to the enantiomer and racemate gels. The $\mathrm{CD}$ experiments performed in the solution sate and gel state revealed the preservation of chirality in gel fibers. The enantiopure gels displayed helical fibers and the racemate showed a tape-like architecture, indicating coassembly of individual enantiomers. The mixed gel of the enantiopure gels displayed twisted tapes, indicating the presence of both enantiomers and racemate gels. This was also confirmed by solid-state NMR studies, where the NMR spectrum of the xerogel of mixed gel displayed both forms. This clearly indicates that in mixed gels system, the fibrils rearrange to form self-sorted and co-assembled fibers. The enhanced mechanical and thermal stability of the mixed gel compared to the enantiomer and racemate gel may be attributed to the presence of both self-sorted and co-assembled fibers. The tuning of mechanical and thermal strength as a function of self-assembly will enable supramolecular chemists to design multicomponent systems with enhanced mechanical and thermal stability.

\section{ASSOCIATED CONTENT}

\section{S Supporting Information}

The Supporting Information is available free of charge on the ACS Publications website at DOI: 10.1021/acs.langmuir.8b02729.

Further gelation test, MGC experiments, $T_{\text {gel }}$ experiments, SEM, and AFM images, CD and OD experiments, rheology, and NMR spectra (PDF)

\section{AUTHOR INFORMATION}

\section{Corresponding Author}

*E-mail: krishna@hi.is. Tel: +354 525 4846. Fax: +354 552 8911.

ORCID

António A. Vicente: 0000-0003-3593-8878

Pall Thordarson: 0000-0002-1200-8814

Krishna K. Damodaran: 0000-0002-9741-2997

Author Contributions

"D.A.T. and D.G. contributed equally to this work.

Notes

The authors declare no competing financial interest.

\section{ACKNOWLEDGMENTS}

We thank University of Iceland Research Fund for financial support. D.G. thanks University of Iceland for the Doctoral Research grant and Z.K. thanks University of Ljubljana for the Erasmus exchange program. We thankfully acknowledge Dr. A. Rawal, The Mark Wainwright Analytical Centre, UNSW for solid state NMR studies and Dr. Sigridur Jónsdóttir, University of Iceland for solution NMR and Mass spectroscopy. P.T. thanks the Australian Research Council for an ARC Centre of Excellence grant (CE140100036) and A.D.M. thanks the National Health and Medical Research Council for a Dementia Development Research Fellowship (APP1106751). L.F. and A.V. thank the FCT (UID/BIO/04469/2013), COMPETE 2020 (POCI-01-0145-FEDER-006684), and Norte2020Programa Operacional Regional do Norte (BioTecNorte operation, NORTE-01-0145-FEDER-000004) for rheological studies. The rheological study was supported by a STSM Grant from COST Action CM1402 Crystallize.

\section{REFERENCES}

(1) Estroff, L. A.; Hamilton, A. D. Water Gelation by Small Organic Molecules. Chem. Rev. 2004, 104, 1201-1218.

(2) de Loos, M.; Feringa, B. L.; van Esch, J. H. Design and Application of Self-Assembled Low Molecular Weight Hydrogels. Eur. J. Org. Chem. 2005, 2005, 3615-3631.

(3) George, M.; Weiss, R. G. Molecular Organogels. Soft Matter Comprised of Low-Molecular-Mass Organic Gelators and Organic Liquids. Acc. Chem. Res. 2006, 39, 489-497.

(4) Dastidar, P. Supramolecular gelling agents: can they be designed? Chem. Soc. Rev. 2008, 37, 2699-2715.

(5) Hirst, A. R.; Escuder, B.; Miravet, J. F.; Smith, D. K. High-Tech Applications of Self-Assembling Supramolecular Nanostructured GelPhase Materials: From Regenerative Medicine to Electronic Devices. Angew. Chem., Int. Ed. 2008, 47, 8002-8018.

(6) Banerjee, S.; Das, R. K.; Maitra, U. Supramolecular gels in action'. J. Mater. Chem. 2009, 19, 6649-6687.

(7) Piepenbrock, M.-O. M.; Lloyd, G. O.; Clarke, N.; Steed, J. W. Metal- and Anion-Binding Supramolecular Gels. Chem. Rev. 2010, $110,1960-2004$

(8) Yu, G.; Yan, X.; Han, C.; Huang, F. Characterization of supramolecular gels. Chem. Soc. Rev. 2013, 42, 6697-6722. 
(9) Kumar, D. K.; Steed, J. W. Supramolecular gel phase crystallization: orthogonal self-assembly under non-equilibrium conditions. Chem. Soc. Rev. 2014, 43, 2080-2088.

(10) Foster, J. A.; Damodaran, K. K.; Maurin, A.; Day, G. M.; Thompson, H. P. G.; Cameron, G. J.; Bernal, J. C.; Steed, J. W. Pharmaceutical polymorph control in a drug-mimetic supramolecular gel. Chem. Sci. 2017, 8, 78-84.

(11) Terech, P.; Weiss, R. G. Low Molecular Mass Gelators of Organic Liquids and the Properties of Their Gels. Chem. Rev. 1997, 97, 3133-3160.

(12) Skilling, K. J.; Citossi, F.; Bradshaw, T. D.; Ashford, M.; Kellam, B.; Marlow, M. Insights into low molecular mass organic gelators: a focus on drug delivery and tissue engineering applications. Soft Matter 2014, 10, 237-256.

(13) Du, X.; Zhou, J.; Shi, J.; Xu, B. Supramolecular Hydrogelators and Hydrogels: From Soft Matter to Molecular Biomaterials. Chem. Rev. 2015, 115, 13165-13307.

(14) Babu, S. S.; Praveen, V. K.; Ajayaghosh, A. Functional $\pi$ Gelators and Their Applications. Chem. Rev. 2014, 114, 1973-2129.

(15) Worthington, P.; Pochan, D. J.; Langhans, S. A. Peptide Hydrogels - Versatile Matrices for 3D Cell Culture in Cancer Medicine. Front Oncol. 2015, 5, 92.

(16) Truong, W. T.; Su, Y.; Meijer, J. T.; Thordarson, P.; Braet, F. Self-Assembled Gels for Biomedical Applications. Chem. Asian J. 2011, 6, 30-42.

(17) Buerkle, L. E.; Rowan, S. J. Supramolecular gels formed from multi-component low molecular weight species. Chem. Soc. Rev. 2012, 41, 6089-6102.

(18) Raeburn, J.; Adams, D. J. Multicomponent low molecular weight gelators. Chem. Commun. 2015, 51, 5170-5180.

(19) Edwards, W.; Smith, D. K. Enantioselective Component Selection in Multicomponent Supramolecular Gels. J. Am. Chem. Soc. 2014, 136, 1116-1124.

(20) Smith, M. M.; Smith, D. K. Self-sorting multi-gelator gelsmixing and ageing effects in thermally addressable supramolecular soft nanomaterials. Soft Matter 2011, 7, 4856-4860.

(21) Fichman, G.; Guterman, T.; Adler-Abramovich, L.; Gazit, E. Synergetic functional properties of two-component single amino acidbased hydrogels. CrystEngComm 2015, 17, 8105-8112.

(22) Singh, N.; Maity, C.; Zhang, K.; Angulo-Pachón, C. A.; van Esch, J. H.; Eelkema, R.; Escuder, B. Synthesis of a Double-Network Supramolecular Hydrogel by Having One Network Catalyse the Formation of the Second. Chem. Eur. J. 2017, 23, 2018-2021.

(23) Singh, N.; Zhang, K.; Angulo-Pachon, C. A.; Mendes, E.; van Esch, J. H.; Escuder, B. Tandem reactions in self-sorted catalytic molecular hydrogels. Chem. Sci. 2016, 7, 5568-5572.

(24) Sandeep, A.; Praveen, V. K.; Kartha, K. K.; Karunakaran, V.; Ajayaghosh, A. Supercoiled fibres of self-sorted donor-acceptor stacks: a turn-off/turn-on platform for sensing volatile aromatic compounds. Chem. Sci. 2016, 7, 4460-4467.

(25) Safont-Sempere, M. M.; Fernández, G.; Würthner, F. SelfSorting Phenomena in Complex Supramolecular Systems. Chem. Rev. 2011, 111, 5784-5814.

(26) Draper, E. R.; Wallace, M.; Schweins, R.; Poole, R. J.; Adams, D. J. Nonlinear Effects in Multicomponent Supramolecular Hydrogels. Langmuir 2017, 33, 2387-2395.

(27) Ramalhete, S. M.; Nartowski, K. P.; Sarathchandra, N.; Foster, J. S.; Round, A. N.; Angulo, J.; Lloyd, G. O.; Khimyak, Y. Z. Supramolecular Amino Acid Based Hydrogels: Probing the Contribution of Additive Molecules using NMR Spectroscopy. Chem. Eur. J. 2017, 23, 8014-8024.

(28) Draper, E. R.; Adams, D. J. How should multicomponent supramolecular gels be characterised? Chem. Soc. Rev. 2018, 47, 3395-3405.

(29) Cross, E. R.; Sproules, S.; Schweins, R.; Draper, E. R.; Adams, D. J. Controlled Tuning of the Properties in Optoelectronic SelfSorted Gels. J. Am. Chem. Soc. 2018, 140, 8667-8670.

(30) Shigemitsu, H.; Fujisaku, T.; Tanaka, W.; Kubota, R.; Minami, S.; Urayama, K.; Hamachi, I. An adaptive supramolecular hydrogel comprising self-sorting double nanofibre networks. Nat. Nanotechnol. 2018, 13, 165-172.

(31) Nanda, J.; Adhikari, B.; Basak, S.; Banerjee, A. Formation of Hybrid Hydrogels Consisting of Tripeptide and Different Silver Nanoparticle-Capped Ligands: Modulation of the Mechanical Strength of Gel Phase Materials. J. Phys. Chem. B 2012, 116, 12235-12244.

(32) Adhikari, B.; Nanda, J.; Banerjee, A. Pyrene-Containing Peptide-Based Fluorescent Organogels: Inclusion of Graphene into the Organogel. Chem. Eur. J. 2011, 17, 11488-11496.

(33) Samanta, S. K.; Subrahmanyam, K. S.; Bhattacharya, S.; Rao, C. N. R. Composites of Graphene and Other Nanocarbons with Organogelators Assembled through Supramolecular Interactions. Chem. Eur. J. 2012, 18, 2890-2901.

(34) Samanta, S. K.; Pal, A.; Bhattacharya, S.; Rao, C. N. R. Carbon nanotube reinforced supramolecular gels with electrically conducting, viscoelastic and near-infrared sensitive properties. J. Mater. Chem. 2010, 20, 6881-6890.

(35) Wang, Q.; Mynar, J. L.; Yoshida, M.; Lee, E.; Lee, M.; Okuro, K.; Kinbara, K.; Aida, T. High-water-content mouldable hydrogels by mixing clay and a dendritic molecular binder. Nature 2010, 463, 339343.

(36) Kato, T.; Hirai, Y.; Nakaso, S.; Moriyama, M. Liquid-crystalline physical gels. Chem. Soc. Rev. 2007, 36, 1857-1867.

(37) Heeres, A.; van der Pol, C.; Stuart, M.; Friggeri, A.; Feringa, B. L.; van Esch, J. Orthogonal Self-Assembly of Low Molecular Weight Hydrogelators and Surfactants. J. Am. Chem. Soc. 2003, 125, 1425214253.

(38) Brizard, A.; Stuart, M.; van Bommel, K.; Friggeri, A.; de Jong, M.; van Esch, J. Preparation of Nanostructures by Orthogonal SelfAssembly of Hydrogelators and Surfactants. Angew. Chem., Int. Ed. 2008, 47, 2063-2066.

(39) Cornwell, D. J.; Okesola, B. O.; Smith, D. K. Hybrid polymer and low molecular weight gels - dynamic two-component soft materials with both responsive and robust nanoscale networks. Soft Matter 2013, 9, 8730-8736.

(40) Cornwell, D. J.; Okesola, B. O.; Smith, D. K. Multidomain Hybrid Hydrogels: Spatially Resolved Photopatterned Synthetic Nanomaterials Combining Polymer and Low-Molecular-Weight Gelators. Angew. Chem., Int. Ed. 2014, 53, 12461-12465.

(41) Wang, J.; Wang, Z.; Gao, J.; Wang, L.; Yang, Z.; Kong, D.; Yang, Z. Incorporation of supramolecular hydrogels into agarose hydrogels-a potential drug delivery carrier. J. Mater. Chem. 2009, 19, $7892-7896$.

(42) Kölbel, M.; Menger, F. M. Molecular Recognition among Structurally Similar Components of a Self-Assembling Soft Material. Langmuir 2001, 17, 4490-4492.

(43) Moffat, J. R.; Smith, D. K. Controlled self-sorting in the assembly of 'multi-gelator' gels. Chem. Commun. 2009, 316-318.

(44) Draper, E. R.; Adams, D. J. Self-sorting shows its true colours. Nat. Chem. 2016, 8, 737-738.

(45) Draper, E. R.; Eden, E. G. B.; McDonald, T. O.; Adams, D. J. Spatially resolved multicomponent gels. Nat. Chem. 2015, 7, 848852.

(46) Morris, K. L.; Chen, L.; Raeburn, J.; Sellick, O. R.; Cotanda, P.; Paul, A.; Griffiths, P. C.; King, S. M.; O’Reilly, R. K.; Serpell, L. C.; Adams, D. J. Chemically programmed self-sorting of gelator networks. Nat. Commun. 2013, 4, No. 1480.

(47) Onogi, S.; Shigemitsu, H.; Yoshii, T.; Tanida, T.; Ikeda, M.; Kubota, R.; Hamachi, I. In situ real-time imaging of self-sorted supramolecular nanofibres. Nat. Chem. 2016, 8, 743-752.

(48) Brizard, A.; Oda, R.; Huc, I. Chirality effects in self-assembled fibrillar networks. Top. Curr. Chem. 2005, 256, 167-218.

(49) Zhang, L.; Jin, Q.; Liu, M. Enantioselective Recognition by Chiral Supramolecular Gels. Chem. Asian J. 2016, 11, 2642-2649.

(50) Leiras, S.; Freire, F.; Quinoa, E.; Riguera, R. Reversible assembly of enantiomeric helical polymers: from fibers to gels. Chem. Sci. 2015, 6, 246-253. 
(51) Engstrom, J. R.; Savyasachi, A. J.; Parhizkar, M.; Sutti, A.; Hawes, C. S.; White, J. M.; Gunnlaugsson, T.; Pfeffer, F. M. Norbornene chaotropic salts as low molecular mass ionic organogelators (LMIOGs). Chem. Sci. 2018, 9, 5233-5241.

(52) Liu, M.; Zhang, L.; Wang, T. Supramolecular Chirality in SelfAssembled Systems. Chem. Rev. 2015, 115, 7304-7397.

(53) Jung, J. H.; Ono, Y.; Hanabusa, K.; Shinkai, S. Creation of Both Right-Handed and Left-Handed Silica Structures by Sol-Gel Transcription of Organogel Fibers Comprised of Chiral Diaminocyclohexane Derivatives. J. Am. Chem. Soc. 2000, 122, 5008-5009.

(54) Hasell, T.; Chong, S. Y.; Jelfs, K. E.; Adams, D. J.; Cooper, A. I. Porous Organic Cage Nanocrystals by Solution Mixing. J. Am. Chem. Soc. 2012, 134, 588-598.

(55) Liu, Z.; Sun, J.; Zhou, Y.; Zhang, Y.; Wu, Y.; Nalluri, S. K. M.; Wang, Y.; Samanta, A.; Mirkin, C. A.; Schatz, G. C.; Stoddart, J. F. Supramolecular Gelation of Rigid Triangular Macrocycles through Rings of Multiple $\mathrm{C}-\mathrm{H} \cdots \mathrm{O}$ Interactions Acting Cooperatively. J. Org. Chem. 2016, 81, 2581-2588.

(56) Čaplar, V.; Frkanec, L.; Vujičić, N. Š.; Žinić, M. Positionally Isomeric Organic Gelators: Structure-Gelation Study, Racemic versus Enantiomeric Gelators, and Solvation Effects. Chem. Eur. J. 2010, 16, 3066-3082.

(57) Frkanec, L.; Zinic, M. Chiral bis(amino acid)- and bis(amino alcohol)-oxalamide gelators. Gelation properties, self-assembly motifs and chirality effects. Chem. Commun. 2010, 46, 522-537.

(58) He, Y.; Bian, Z.; Kang, C.; Gao, L. Self-discriminating and hierarchical assembly of racemic binaphthyl-bisbipyridines and silver ions: from metallocycles to gel nanofibers. Chem. Commun. 2011, 47, $1589-1591$.

(59) Shen, Z.; Wang, T.; Liu, M. Tuning the Gelation Ability of Racemic Mixture by Melamine: Enhanced Mechanical Rigidity and Tunable Nanoscale Chirality. Langmuir 2014, 30, 10772-10778.

(60) Lin, J.; Guo, Z.; Plas, J.; Amabilino, D. B.; De Feyter, S.; Schenning, A. P. H. J. Homochiral and heterochiral assembly preferences at different length scales - conglomerates and racemates in the same assemblies. Chem. Commun. 2013, 49, 9320-9322.

(61) Borges, A. R.; Hyacinth, M.; Lum, M.; Dingle, C. M.; Hamilton, P. L.; Chruszcz, M.; Pu, L.; Sabat, M.; Caran, K. L. Self-Assembled Thermoreversible Gels of Nonpolar Liquids by Racemic Propargylic Alcohols with Fluorinated and Nonfluorinated Aromatic Rings. Langmuir 2008, 24, 7421-7431.

(62) Amemiya, R.; Mizutani, M.; Yamaguchi, M. Two-Component Gel Formation by Pseudoenantiomeric Ethynylhelicene Oligomers. Angew. Chem., Int. Ed. 2010, 49, 1995-1999.

(63) Swanekamp, R. J.; DiMaio, J. T. M.; Bowerman, C. J.; Nilsson, B. L. Coassembly of Enantiomeric Amphipathic Peptides into Amyloid-Inspired Rippled $\beta$-Sheet Fibrils. J. Am. Chem. Soc. 2012, 134, 5556-5559.

(64) Suzuki, M.; Hanabusa, K. l-Lysine-based low-molecular-weight gelators. Chem. Soc. Rev. 2009, 38, 967-975.

(65) Edwards, W.; Smith, D. Chiral Assembly Preferences and Directing Effects in Supramolecular Two-Component Organogels. Gels 2018, 4, 31.

(66) Das, R. K.; Kandanelli, R.; Linnanto, J.; Bose, K.; Maitra, U. Supramolecular Chirality in Organogels: A Detailed Spectroscopic, Morphological, and Rheological Investigation of Gels (and Xerogels) Derived from Alkyl Pyrenyl Urethanes. Langmuir 2010, 26, 1614116149 .

(67) Nagy, K. J.; Giano, M. C.; Jin, A.; Pochan, D. J.; Schneider, J. P. Enhanced Mechanical Rigidity of Hydrogels Formed from Enantiomeric Peptide Assemblies. J. Am. Chem. Soc. 2011, 133, 1497514977.

(68) Adhikari, B.; Nanda, J.; Banerjee, A. Multicomponent hydrogels from enantiomeric amino acid derivatives: helical nanofibers, handedness and self-sorting. Soft Matter 2011, 7, 8913-8922.

(69) Cicchi, S.; Ghini, G.; Lascialfari, L.; Brandi, A.; Betti, F.; Berti, D.; Baglioni, P.; Di Bari, L.; Pescitelli, G.; Mannini, M.; Caneschi, A. Self-sorting chiral organogels from a long chain carbamate of 1benzyl-pyrrolidine-3,4-diol. Soft Matter 2010, 6, 1655-1661.
(70) Nagy-Smith, K.; Beltramo, P. J.; Moore, E.; Tycko, R.; Furst, E. M.; Schneider, J. P. Molecular, Local, and Network-Level Basis for the Enhanced Stiffness of Hydrogel Networks Formed from Coassembled Racemic Peptides: Predictions from Pauling and Corey. ACS Cent Sci. 2017, 3, 586-597.

(71) George, M.; Weiss, R. G. Low Molecular-Mass Organic Gelators. In Molecular Gels: Materials with Self-Assembled Fibrillar Networks. In Weiss, R. G., Terech, P., Eds.; Springer: Dordrecht, Netherlands, 2006; pp 449-551.

(72) Schön, E.-M.; Marqués-López, E.; Herrera, R. P.; Alemán, C.; Díaz, D. D. Exploiting Molecular Self-Assembly: From Urea-Based Organocatalysts to Multifunctional Supramolecular Gels. Chem. Eur. J. 2014, 20, 10720-10731.

(73) Steed, J. W. Anion-tuned supramolecular gels: a natural evolution from urea supramolecular chemistry. Chem. Soc. Rev. 2010 , 39, 3686-3699.

(74) Isare, B.; Pensec, S.; Raynal, M.; Bouteiller, L. Bisurea-based supramolecular polymers: From structure to properties. C. R. Chim. 2016, 19, 148-156.

(75) George, M.; Tan, G.; John, V. T.; Weiss, R. G. Urea and Thiourea Derivatives as Low Molecular-Mass Organogelators. Chem. Eur. J. 2005, 11, 3243-3254.

(76) Kumar, D. K.; Jose, D. A.; Das, A.; Dastidar, P. First snapshot of a nonpolymeric hydrogelator interacting with its gelling solvents. Chem. Commun. 2005, 4059-4061.

(77) Kotova, O.; Daly, R.; dos Santos, C. M. G.; Boese, M.; Kruger, P. E.; Boland, J. J.; Gunnlaugsson, T. Europium-Directed SelfAssembly of a Luminescent Supramolecular Gel from a Tripodal Terpyridine-Based Ligand. Angew. Chem., Int. Ed. 2012, 51, 72087212.

(78) Piepenbrock, M.-O. M.; Lloyd, G. O.; Clarke, N.; Steed, J. W. Gelation is crucially dependent on functional group orientation and may be tuned by anion binding. Chem. Commun. 2008, 2644-2646.

(79) Schoonbeek, F. S.; van Esch, J. H.; Hulst, R.; Kellogg, R. M.; Feringa, B. L. Geminal bis-ureas as gelators for organic solvents: Gelation properties and structural studies in solution and in the gel state. Chem. Eur. J. 2000, 6, 2633-2643.

(80) Padrela, L.; Rodrigues, M. A.; Velaga, S. P.; Matos, H. A.; Azevedo, E. G. d. Formation of indomethacin-saccharin cocrystals using supercritical fluid technology. Eur. J. Pharm. Sci. 2009, 38, 9-17.

(81) Foster, J. A.; Edkins, R. M.; Cameron, G. J.; Colgin, N.; Fucke, K.; Ridgeway, S.; Crawford, A. G.; Marder, T. B.; Beeby, A.; Cobb, S. L.; Steed, J. W. Blending Gelators to Tune Gel Structure and Probe Anion-Induced Disassembly. Chem. Eur. J. 2014, 20, 279-291.

(82) Lloyd, G. O.; Piepenbrock, M.-O. M.; Foster, J. A.; Clarke, N.; Steed, J. W. Anion tuning of chiral bis(urea) low molecular weight gels. Soft Matter 2012, 8, 204-216.

(83) Foster, J. A.; Johnson, D. W.; Pipenbrock, M.-O. M.; Steed, J. W. Using gel morphology to control pore shape. New J. Chem. 2014, 38, 927-932.

(84) Smith, D. K. Lost in translation? Chirality effects in the selfassembly of nanostructured gel-phase materials. Chem. Soc. Rev. 2009, 38, 684-694.

(85) Makarević, J.; Jokić, M.; Raza, Z.; Štefanić, Z.; Kojić-Prodić, B.; Žinić, M. Chiral Bis(amino alcohol)oxalamide Gelators-Gelation Properties and Supramolecular Organization: Racemate versus Pure Enantiomer Gelation. Chem. Eur. J. 2003, 9, 5567-5580.

(86) Watanabe, Y.; Miyasou, T.; Hayashi, M. Diastereomixture and Racemate of myo-Inositol Derivatives, Stronger Organogelators than the Corresponding Homochiral Isomers. Org. Lett. 2004, 6, 15471550.

(87) Friggeri, A.; van der Pol, C.; van Bommel, K. J. C.; Heeres, A.; Stuart, M. C. A.; Feringa, B. L.; van Esch, J. Cyclohexane-Based Low Molecular Weight Hydrogelators: A Chirality Investigation. Chem. Eur. J. 2005, 11, 5353-5361.

(88) Wu, X.; Ji, S.; Li, Y.; Li, B.; Zhu, X.; Hanabusa, K.; Yang, Y. Helical Transfer through Nonlocal Interactions. J. Am. Chem. Soc. 2009, 131, 5986-5993. 
(89) Gottarelli, G.; Lena, S.; Masiero, S.; Pieraccini, S.; Spada, G. P. The use of circular dichroism spectroscopy for studying the chiral molecular self-assembly: An overview. Chirality 2008, 20, 471-485.

(90) Krysmann, M. J.; Castelletto, V.; McKendrick, J. E.; Clifton, L. A.; Hamley, I. W.; Harris, P. J. F.; King, S. M. Self-Assembly of Peptide Nanotubes in an Organic Solvent. Langmuir 2008, 24, 81588162.

(91) Gupta, M.; Bagaria, A.; Mishra, A.; Mathur, P.; Basu, A.; Ramakumar, S.; Chauhan, V. S. Self-Assembly of a DipeptideContaining Conformationally Restricted Dehydrophenylalanine Residue to Form Ordered Nanotubes. Adv. Mater. 2007, 19, 858-861. 